\title{
Device Difficult to Prepare
}

National Cancer Institute

\section{Source}

National Cancer Institute. Device Difficult to Prepare. NCI Thesaurus. Code C63010.

Problem associated with the use of the device in terms of user experiencing difficulty in preparing device for use, even if the operation is being performed according to labeled instructions for use. 